\title{
ОБ ОДНОМ ПОДХОДЕ К СИНТЕЗУ МЕДИЦИНСКИХ ИНФОРМАЦИОННЫХ СИСТЕМ ВЕДЕНИЯ ЭЛЕКТРОННОЙ ДОКУМЕНТАЦИИ
}

\author{
А. С. Солодовников, О. В. Зайцева, В. Г. Книгавко, М. А. Бондаренко, \\ Е. Б. Радзишевская \\ Харьковский национальный медицинский университет
}

\section{AN APPROACH TO THE SYNTHESIS OF THE MEDICAL INFORMATION SYSTEM FOR ELECTRONIC DOCUMENTATION}

\section{A. S. Solodovnikov, O. V. Zaitseva, V. H. Knyhavko, M. A. Bondarenko, E. B. Radzyshevska \\ Kharkiv National Medicine University}

\begin{abstract}
Введение. Электронный способ ведения документов обладает рядом преимуществ, позволяющих упростить процессы обработки, обмена, хранения информации, защиты медико-биологических данных и организации консультаций медицинских специалистов.

Существующая задача перехода от бумажного способа ведения медицинской документации к электронному остается до сих пор актуальной, о чем говорит разнообразие стандартов ведения электронных медицинских записей: например, стандарты HL7, DICOM и другие.
\end{abstract}

Результаты и их обсуждение. Успех внедрения систем электронного документооборота напрямую зависит от решения задач разработки программного обеспечения (ПО) информационных систем (ИС).

В процессе создания конкурентоспособного ПО важно как обеспечить соблюдение основных показателей качества (например, стандарт ISO/ IEC 25051:2014), так и оптимизировать или снизить влияние человеческого фактора на быстродействие программного средства (ПС). Для сложных ПрО и для разрабатываемых ИС становится актуальным вопрос оптимизации действий, сокращение времени диалога пользователя с системой. Для этого необходимы специальные методы синтеза и реализую- щие их инструментальные средства создания программных комплексов (ПК) для заданных ПрО - в частности, для медицинских ИС.

Для обеспечения автоматизации процесса синтеза необходимо наличие формализованного описания ПрО и структуры ПС вместе с требованиями к конечному продукту. Данная информация служит основой для получения ПК с применением разноязычных программных модулей и различных технологий программирования.

Предлагается развитие и применение информационной технологии синтеза проблемноориентированных ПК для организации электронного документооборота в медицинских ИС с использованием разработанного инструментария разработчика (стандарт IEEE P1484.1/D11) (рис. 1).

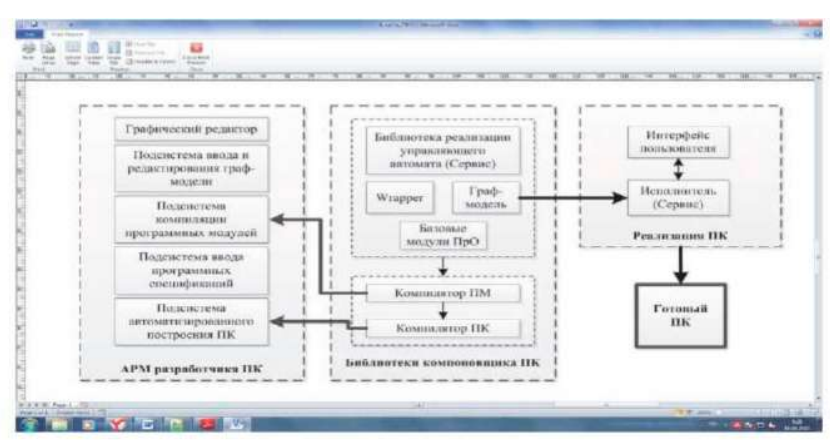

Puc. 1. Архитектура программного средства разработчика «SWDesigner». 